\title{
OS MODELOS DE POLÍTICA LINGÜÍSTICA DE GALICIA
}

\section{Antón Losada}

Universidade de Santiago de Compostela 



\section{AS POLÍTICAS LINGÜÍSTICAS EN GALICIA DURANTE A ERA FRAGA}

A Lei 3/1983, do 15 de xuño, de normalización lingüística desenvolve o disposto na Constitución española de 1978 (art. 3) e no Estatuto de autonomía de Galicia de 1981 (art. 5). A raíz de ambos os textos legais, a lei garante que o galego e o español son idiomas oficiais en Galicia, e tamén garante o proceso de normalización do galego como lingua propia da Comunidade Autónoma.

Esta Lei consta de 6 títulos e 25 artigos. Por primeira vez, un texto legal inclúe unha regulación completa e planificación para a promoción do uso do galego como lingua oficial, incluso en áreas e espazos nos que tradicionalmente non se permitía - mesmo se perseguía - o uso do galego como consecuencia dunhas circunstancias históricas, políticas e socias concretas. Deste xeito, a Lei regula a normalización no uso do galego nas diferentes administracións (autonómicas, locais e de xustiza) e no sistema educativo, os medios de comunicación e tamén nas comunidades de fóra de Galicia.

O primeiro artigo declara o galego como a lingua propia de Galicia. Os galegos teñen o dereito, pero non a obriga, de coñecela e utilizala. Isto ten unha dobre consecuencia: (i) o galego é o idioma oficial (o español tamén) nas institucións da Comunidade Autónoma e na Administración, Administración local e sociedades públicas en función da Comunidade Autónoma, e (ii) a Administración galega ten que adoptar as decisións precisas para garantir un uso xeneralizado e un uso legal do galego (igual que do español).

A Lei regula o uso do galego nos diferentes niveis administrativos no territorio galego. A Administración autonómica asume a dirección técnica e seguimento de todo o proceso de normalización lingüística: regulación, orzamento, promoción, información, etc. A Xunta ten que elaborar un plan. O plan de nor- 
malización do idioma galego forma parte da herdanza histórica da Comunidade e debe aplicar as decisións dos seguintes obxectivos específicos:

(i) estender o uso do galego entre o funcionariado público autonómico;

(ii) asegurar o dereito da cidadanía a usar o galego na súa relación coa Administración;

(iii) asegurar o uso do galego en calquera tipo de documento oficial;

(iv) asegurar que os topónimos en galego sexan os únicos recoñecidos pola Xunta de Galicia;

(v) favorecer a promoción e uso do galego como lingua normal no comercio, publicidade, cultura, deportes e actividades polo estilo;

(vi) dirixir e asegurar unha progresiva normalización do uso do galego na xustiza e na Administración local.

A cidadanía pode usar o galego e o castelán na súa relación co sistema de xustiza. Ten dereito a recibir notificacións na lingua oficial que elixa. $\mathrm{O}$ coñecemento do galego dentro desta Administración é concibido coma un mérito para a promoción.

A Lei 3/1983, desenvolta no Decreto 247/1995, considera o galego como lingua oficial de educación e establece o estudo do galego como unha materia obrigatoria en todos os niveis educativos. A aposta era o bilingüismo hamónico, protexido por dous preceptos: os estudantes teñen dereito á primeira educación na súa lingua materna (aprendizaxe da lingua oficial de Galicia ao mesmo tempo) e prohíbese calquera separación dos estudantes en aulas e escolas por idiomas.

Galicia e Cataluña son as únicas comunidades autónomas históricas que optaron polo modelo AA de bilingüismo total: o goberno autonómico elixe o idioma oficial dun sistema educativo bilingüe. Dentro dese sistema, cada escola tiña un grao considerable de autonomía para desenvolver o proceso de normalización de acordo cos recursos dispoñibles, o coñecemento da lingua oficial entre o profesorado e as asociacións de pais de alumnos.

A promoción do galego nas escolas operaba de dúas maneiras: (i) o uso obrigatorio do galego en calquera tipo de traballo administrativo interno, (ii) polo menos, ensino parello do galego e do español. Neste sentido, o Decreto especificaba as áreas de coñecemento e as materias que se imparten en galego. Tanto na educación primaria como na secundaria obrigatoria, o galego emprégase para ensinar as materias máis próximas ao medio natural: ciencias sociais (xeo- 
grafía e historia) e ciencias naturais. Por un lado, nos niveis elevados a oferta está diversificada: filosofía, tecnoloxía, debuxo, arte, ciencias políticas, socioloxía...; por outro lado, na formación politécnica (nivel intermedio) os estudantes tenden a recibir a educación en galego para as áreas técnicas de coñecemento práctico.

O obxectivo xeral desta proposta era garantir que cando os estudantes conclúan esta fase educativa saiban galego, tanto a nivel oral como escrito. Pero este obxectivo vese atenuado polo que podemos chamar «un dereito básico á educación»: asegurar que a educación (formación) prevalece sobre o uso ou non do galego. Os profesores adoptarán as medidas precisas para asegurar que aqueles estudantes que non teñen coñecemento suficiente do galego poidan aprender as materias impartidas nesta lingua sen problemas.

O dereito a elixir prevalece no nivel universitario. Os estudantes e profesores teñen dereito a usar a lingua oficial que prefiran; aínda que a Xunta de Galicia e as autoridades universitarias teñen que tomar as decisións axeitadas para normalizar o uso do galego. Deste xeito, a Lei 3/1983 obriga a (i) estudar a lingua galega nas escolas universitarias e en calquera tipo de centros de formación profesional para docentes e (ii) promover o uso do galego entre o profesorado en todos os niveis de educación.

A Lei tamén contemplaba que o galego fose a lingua de uso normal na radio, na televisión e noutros medios sociais de comunicación que sexan propiedade das institucións da Comunidade Autónoma. O goberno da Xunta de Galicia debe dar apoio económico e material aos medios de comunicación co fin de promover e estimular as manifestacións culturais, espectáculos, así como a exhibición e produción de filmes e a divulgación de libros feitos en galego.

Falando en termos económicos, no orzamento e recursos, os datos mostran un incremento notable e constante dos recursos totais asignados para apoiar e estender o uso do galego ao longo deste ano.

Especialmente relevantes son os recursos destinados a incrementar o uso do galego nos medios de comunicación, xa que este diñeiro público estase a converter nunha fonte moi importante de recursos para os medios de comunicación de Galicia e o seu mercado moi limitado de lectores e espectadores.

Tamén os recursos empregados a favor da edición e impresión de libros en galego son moi importantes para crear e consolidar un mercado específico para 
os lectores en galego e a produción cultural mediante o galego. De feito, a Xunta é o principal editor galego: máis do $50 \%$ dos libros escritos en galego son editados e impresos polo goberno autonómico.

- A actividade de promoción da lingua galega: asociacións, institucións sen fins de lucro, entidades similares

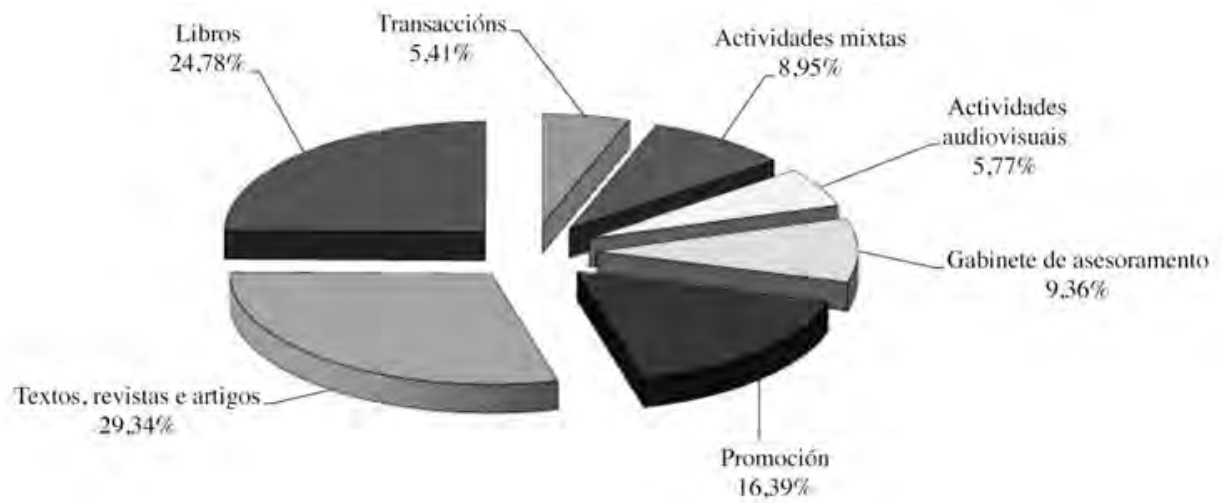

- As actividades da lingua galega dos fondos de promoción no sector empresarial

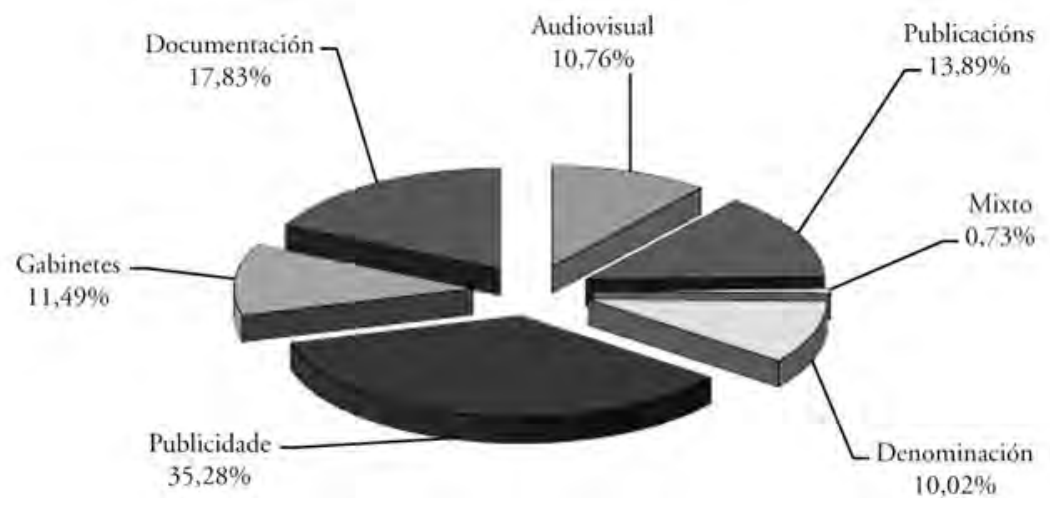

Unha maioría moi clara e firme mostrou un constante apoio durante este período ás políticas e recursos destinados a fomentar o uso do galego. Só de vez en cando os conflitos moi locais chegaron ao público e promoveron o debate arredor da cuestión lingüística. 
Pero isto non significa que toda a cidadanía galega teña a mesma opinión e percepcións acerca do galego. Hai diferenzas moi claras no referente ás actitudes cara ao galego en razón do sexo, familia, educación e hábitat. O galego é máis valorado entre os homes, na escola pública e nos hábitats rurais ou semirurais. $\mathrm{O}$ español é máis valorado entre as mulleres, na escola privada e nos ámbitos urbanos; tamén, en termos de motivación para a aprendizaxe do galego, unha clara maioría ten unha percepción positiva (Lameiras Fernández e González Lorenzo, 1996).

- Táboa 1. Lingua propia, por lugar de aprendizaxe

\begin{tabular}{lllll} 
Lugar & Só español & Máis español & Máis galego & Só galego \\
\hline Familia & $3,0 \%$ & $16,1 \%$ & $34,0 \%$ & $47,0 \%$ \\
\hline Escola & $42,1 \%$ & $50,0 \%$ & $6,5 \%$ & $1,4 \%$ \\
\hline Amigos & $26,1 \%$ & $47,2 \%$ & $23,0 \%$ & $3,7 \%$ \\
\hline Veciños & $38,0 \%$ & $41,6 \%$ & $17,7 \%$ & $2,7 \%$ \\
\hline Traballo & $25,1 \%$ & $54,6 \%$ & $18,5 \%$ & $1,7 \%$ \\
\hline
\end{tabular}

Fonte: MSG, vol. II, 1995

Unha parte moi significativa da xente que ten o galego como idioma de preferencia son persoas maiores, de clase social baixa e tamén con baixos niveis de educación; pero, dende o inicio deste proceso de normalización, hai unha incorporación cada vez maior e constante dos mozos de clase media urbana, con altos niveis de educación, que prefiren e valoran o uso do galego.

Esta etapa vén marcada por unha clara maioría que apoia abertamente a galeguización dos sistemas de educación (MSG, vol. II, p. 557). Isto significa que a maioría da xente en Galicia apoia a extensión da aprendizaxe en galego a todos os niveis do sistema educativo.

- Táboa 2. Utilidades comparativas dos idiomas

\begin{tabular}{llll} 
& Galego máis usado & Ambos & Español máis usado \\
\hline Persoas que estudaron galego & $11,4 \%$ & $67,9 \%$ & $20,7 \%$ \\
\hline Persoas que non & $11,3 \%$ & $54,3 \%$ & $34,3 \%$ \\
\hline
\end{tabular}

Fonte: MSG, vol. III, 1996 
- Táboa 3. Lingua que debe ser ensinada aos nenos na casa

\begin{tabular}{lll} 
Español & Ambos & Galego \\
\hline $6,6 \%$ & $72,0 \%$ & $21,4 \%$ \\
\hline
\end{tabular}

Fonte: MSG, vol. III, 1996

O galego recuperou espazo en Galicia: máis da metade da poboación galega fala galego de xeito exclusivo $(38,7 \%)$ ou como lingua preferente $(29,9 \%)$ (MSG, datos de 1995). Pero o bilingüismo é habitual para a xente en Galicia. A maioría ten unha percepción positiva sobre o español en termos da súa utilidade e uso no traballo, pero tamén hai unha nova maioría en aumento que ten tamén unha percepción positiva acerca dos usos e utilidades do galego (Lameiras Fernández e González Lorenzo, 1996). Especialmente relevante foi o crecemento e a consolidación do uso do galego nas zonas urbanas e nas clases medias, onde tradicionalmente fora a segunda e incluso a terceira opción.

- Táboa 4. Distribución da primeira lingua en Galicia

\begin{tabular}{ll} 
Idioma & $\%$ \\
\hline Galego & $62,4 \%$ \\
\hline Español & $25,6 \%$ \\
\hline Ambos & $11,4 \%$ \\
\hline Outros & $0,6 \%$ \\
\hline
\end{tabular}

Fonte: MSG, vol. I, 1994

- Táboa 5. Idioma principal: por hábitat

\begin{tabular}{lllll} 
Hábitat & Só español & Máis español & Máis galego & Só galego \\
\hline Urbano & $21,6 \%$ & $35,8 \%$ & $30,9 \%$ & $11,8 \%$ \\
\hline Semiurbano & $10,6 \%$ & $24,1 \%$ & $33,6 \%$ & $31,8 \%$ \\
\hline Rural & $3,2 \%$ & $9,6 \%$ & 28,2 & $59,0 \%$ \\
\hline
\end{tabular}

Fonte: MSG, vol. II, 1995 
- Táboa 6. Idioma principal: por clase social

\begin{tabular}{lllll} 
Clase social & Só español & Máis español & Máis galego & Só galego \\
\hline Media-baixa & $6,0 \%$ & $14,7 \%$ & $31,6 \%$ & $47,7 \%$ \\
\hline Media & $14,4 \%$ & $27,0 \%$ & $29,4 \%$ & $29,2 \%$ \\
\hline Media-alta & $27,7 \%$ & $37,7 \%$ & $21,2 \%$ & $14,1 \%$ \\
\hline
\end{tabular}

Fonte: MSG, vol. II, 1995

É posible falar dunha especie de reequilibrio do bilingüismo en Galicia: máis xente fala, usa e valora o galego. Isto non significa que esas persoas non falen, usen ou valoren o español ao mesmo tempo. Máis xente fala, escribe e le en galego ca nunca na nosa historia recente. Logo da persecución que sufriu o galego no marco do réxime de Franco, podemos falar agora dunha clara recuperación do uso do galego, á parte dunha restauración completa dos valores sociais e apreciativos do galego como lingua propia de Galicia. Isto non se fixo por oposición ou competencia co español. Os galegos coñecen as dúas linguas e usan ambas.

- Táboa 7. Evolución da lingua habitual (1877-1995): monolingüismo

\begin{tabular}{lllllllll} 
& 1877 & 1897 & 1917 & 1924 & 1947 & 1967 & 1974 & 1995 \\
\hline Só galego & $88,5 \%$ & $84,7 \%$ & $79,0 \%$ & $71,6 \%$ & $32,4 \%$ & $30,8 \%$ & $17,7 \%$ & $38,7 \%$ \\
\hline Só español & $2,9 \%$ & $3,8 \%$ & $5,8 \%$ & $5,7 \%$ & $9,0 \%$ & $13,0 \%$ & $20,5 \%$ & $10,6 \%$ \\
\hline
\end{tabular}

Fonte: MSG, vol. II, 1995

- Táboa 8. Evolución da lingua habitual (1877-1995): bilingüismo

\begin{tabular}{lllllllll} 
& 1877 & 1897 & 1917 & 1924 & 1947 & 1967 & 1974 & 1995 \\
\hline Máis galego & $7,3 \%$ & $8,9 \%$ & $10,2 \%$ & $18,0 \%$ & $38,5 \%$ & $29,1 \%$ & $22,0 \%$ & $29,9 \%$ \\
\hline Máis español & $1,4 \%$ & $2,6 \%$ & $5,0 \%$ & $4,6 \%$ & $20,1 \%$ & $26,9 \%$ & $39,8 \%$ & $20,8 \%$ \\
\hline
\end{tabular}

Fonte: MSG, vol. II, 1995 
- Táboa 9. Coñecemento efectivo nas catro habilidades básicas

\begin{tabular}{ll} 
Habilidades & \% \\
\hline Entenden & $97,1 \%$ \\
\hline Falan & $86,4 \%$ \\
\hline Len & $45,9 \%$ \\
\hline Escriben & $27,1 \%$ \\
\hline
\end{tabular}

Fonte: MSG, vol. I, 1994

- Táboa 10. Coñecemento efectivo nas catro habilidades básicas, por primeira lingua

\begin{tabular}{llll} 
Habilidades & Galego & Español & Ambos \\
\hline Entenden & $99,4 \%$ & $91,7 \%$ & $97,3 \%$ \\
\hline Falan & $97,9 \%$ & $58,7 \%$ & $87,3 \%$ \\
\hline Len & $40,1 \%$ & $56,1 \%$ & $53,7 \%$ \\
\hline
\end{tabular}

Fonte: MSG, vol. I, 1994

Algúns datos adicionais, pero moi significativos, pódennos axudar a comprender a verdadeira extensión e significado deste reequilibrio do bilingüismo tradicional en Galicia:

(i) a interacción entre a Xunta e a Administración local (documentos e comunicación formais e informais, actos oficiais, etc.) está a ter un impacto significativo sobre un uso crecente e percepción do galego como idioma oficial da rexión (MSG, vol. II, p. 364);

(ii) existe unha crecente maioría que percibe o galego como unha lingua precisa para as súas interaccións e relacións con calquera tipo de institucións, públicas ou privadas, políticas e sociais (MSG, vol. II, p. 364),

(iii) unha maioría (60\%) non lle atribúe a mesma utilidade como lingua e aínda pensa que o español é máis útil. 
- Táboa 11. As percepcións da xente sobre o uso do galego

\begin{tabular}{llll} 
& Hai 10 anos & Hai 25 anos & Hai 40 anos \\
\hline Máis usada ca & $75,5 \%$ & $66,9 \%$ & $51,2 \%$ \\
\hline Usado menos ca & $12,9 \%$ & $20,8 \%$ & $27,6 \%$ \\
\hline Igualdade de uso & $11,5 \%$ & $12,3 \%$ & $11,1 \%$
\end{tabular}

Fonte: MSG, vol. III, 1996

- Táboa 12. A evolución da estima cara ao galego, por idade

\begin{tabular}{llll} 
& Menos & Igual & Máis \\
\hline Sen estudos & $2,1 \%$ & $60,9 \%$ & $37 \%$ \\
\hline Educación elemental & $2,8 \%$ & $49,7 \%$ & $47,6 \%$ \\
\hline Educación media & $4,2 \%$ & $42,4 \%$ & $53,4 \%$ \\
\hline Universidade & $3,9 \%$ & $41,9 \%$ & $54,2 \%$
\end{tabular}

Fonte: MSG, vol. III, 1996

Existía, tamén, unha percepción clara entre o pobo galego acerca de quen é o responsable da cuestión e o proceso de normalización lingüística, a política e os políticos, na seguinte orde: Xunta de Galicia, concellos, sistema educativo e medios de comunicación, especialmente os medios de comunicación públicos (MSG, vol. III, p. 453, 1996). Tamén hai unha percepción clara da relación entre o futuro e o destino do galego e o destino e o futuro de Galicia como nación.

De feito, o debate lingüístico en Galicia non versou nunca nestes anos sobre o uso ou non do galego. Había unha maioría social moi clara que apoiaba e favorecía as políticas activas para aumentar e mellorar o uso do galego en todos os niveis da vida pública e privada.

O verdadeiro debate xiraba máis arredor do grao de compromiso real dos actores políticos e o goberno rexional no proceso de normalización do galego como lingua oficial de Galicia. 
- Táboa 13. Que pasará coa identidade nacional de Galicia e a cultura galega se o galego desaparece? Por nivel de estudos

\begin{tabular}{lll} 
Nivel de estudos & Tamén desaparecerá & Non desaparecerá \\
\hline Sen estudos & $70 \%$ & $30 \%$ \\
\hline Educación básica & $74,8 \%$ & $25,2 \%$ \\
\hline Educación media & $82,5 \%$ & $17,5 \%$ \\
\hline Universidade & $80,6 \%$ & $19,4 \%$ \\
\hline
\end{tabular}

Fonte: MSG, vol. III, 1996

A pesar das intencións formais e legais declaradas pola Lei 3/1983, e por algúns decretos que a desenvolven, a política lingüística da Administración autonómica acreditou carencias severas durante estes 17 anos de aplicación, cambios, intentos de execución e máis cambios.

Un estudo feito no seu tempo polo propio goberno autonómico sobre o Decreto 247/1995 mostrou o seu cumprimento insuficiente, en todos os niveis educativos, tanto en materias e horas impartidas en galego como na falta de planificación lingüística real na maioría das escolas primarias e secundarias.

Hai moitas razóns que poden explicar os resultados desiguais da política lingüística en Galicia. Algunhas delas veñen sintetizas no propio Plan xeral de normalización da lingua galega (PXNLG) que o Parlamento aprobou por unanimidade en 2004 e no que se facía unha severa análise dos resultados das políticas lingüísticas e se propuñan medidas específicas de reforma e mellora:

1. A Dirección Xeral de Política Lingüística (DXPL) pertenceu sempre á Consellería de Educación. Non houbo nunca dende a Xunta nin unha visión global nin unha unidade interdepartamental que levase adiante un plan en todos os campos posibles acerca da política lingüística que Galicia precisa.

2. A política lingüística da Xunta careceu de planificación. Non había obxectivos concretos e as liñas de acción non estaban determinadas. $\mathrm{O}$ deseño da política non contemplaba a normalización lingüística usando unha perspectiva xeral.

3. A visión do goberno autonómico sobre a normalización non foi moi ambiciosa. O obxectivo principal pareceu ser evitar a morte do galego, aumentar e entender o seu uso. Neste sentido, a defensa do bilingüismo harmónico na edu- 
cación non trouxo ningún avance significativo na normalización. Esta política deulle gran cobertura á educación en español e non tratou de resolver a non aplicación sistemática da lexislación sobre os temas e horas destinadas á educación en galego.

4. Hai unha falta de control real dos resultados das políticas. De feito, esta é unha das características esenciais do modelo do bilingüismo harmónico: dotar a súa implementación dun carácter voluntario que equilibre a potencia das súas declaracións simbólicas a prol da normalización.

\section{A POLÍTICA LINGÜÍSTICA DO GOBERNO BIPARTITO}

O cambio de goberno trouxo consigo un cambio substancial da política lingüística, en boa medida moi axustado á estratexia e ás medidas de cambio incluídas no PXNLG do ano 2004. A nova política que pactan, non sen dificultades, os dous socios de goberno combina a visión de «emerxencia» da situación da lingua dominante entre os nacionalistas e a visión máis pragmática dominante entre os socialistas.

\section{Algúns datos de partida}

O MSG-04 analiza os usos lingüisticos en Galicia a partir dun inquérito realizado en 2004 a máis de 9000 persoas de entre 15 e 54 anos. O cambio metodolóxico con respecto á entrega anterior dificulta en extremo a comparación dos resultados obtidos, pero, aínda así, pódense remarcar algúns indicadores que nos poden servir para ter unha imaxe de como evolucionou a situación. Os datos de 2004 revelan:

O bilingüismo é claramente predominante no país (57,9\%).

O uso máis estendido é o bilingüe, con predominio notable de castelán $(35,3 \%)$.

O uso do galego sae minoritario respecto ao do castelán $(38,4 \%$ fronte ao $61,1 \%)$. 
- Evolución da lingua habitual en Galicia (tramo de 16-54 anos)

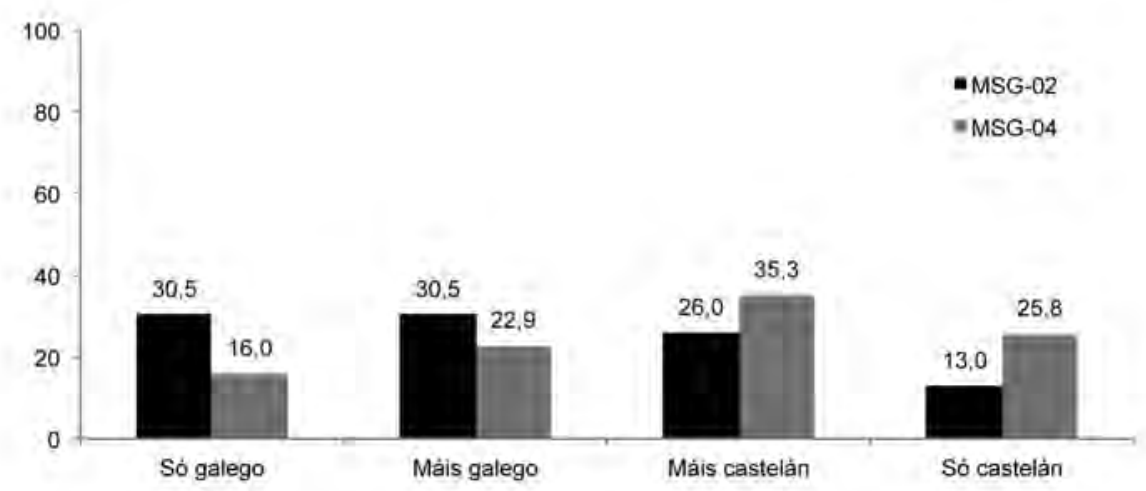

(Fonte: USC, Área de Dinamización Lingüística, 2009)

Retrocede o monolingüismo en galego (14,5 puntos) ao tempo que medra o monolingüismo en castelán (12,8 puntos). De feito, un de cada dez nenos non estudou galego.

Outros datos de interese destácanse no informe da Área de Dinamización Lingüística da USC:

Ao interrelacionar lingua habitual e lingua inicial, a retención do castelán é, en conxunto (monolingües e bilingües), maior ca a do galego. Visto en perspectiva dende 1992, hai un maior mantemento do monolingüismo, especialmente marcado nos castelanfalantes iniciais.

O uso do galego é maior coa competencia lingüística máis alta, mais son moi elevadas as porcentaxes de castelanfalantes habituais que se adscriben ao nivel de maior competencia en galego. Tamén en relación co MSG-92, descende o uso habitual do galego nos niveis de competencia máis altos: recuperar unha lingua non é só cuestión de competencia lingüística.

De novo o lugar de nacemento e, sobre todo, o hábitat de residencia teñen un peso marcado nos usos lingüísticos: o $70 \%$ dos falantes de só ou maioritariamente galego viven en concellos de menos de 5000 habitantes e o 75,7\% dos castelanfalantes (só ou predominantemente) nos de máis de 5000 . 
En relación con 1992, sobrancea a estabilidade do uso exclusivo do galego e o avance do monolingüismo castelán no urbano; a caída do bilingüismo con predominio do galego nos hábitats intermedios a prol do castelán e a forte caída do galego no rural. Ferrol e Vigo son as cidades máis castelanizadas: o $57,5 \%$ e o $45,4 \%$ son monolingües en castelán, respectivamente; Santiago e Lugo, as de maior uso do galego (41,9\% e 40,5\%, respectivamente).

Con respecto á evolución do proceso de normalización lingüística, os datos do Observatorio da Lingua Galega parecen apuntalar un dobre resultado. A normalización avanza máis no eido institucional ca no social. As institucións falan máis galego, pero a xente non tanto.

- Táboa 14. Comparativa do Índice de Normalización Lingüística

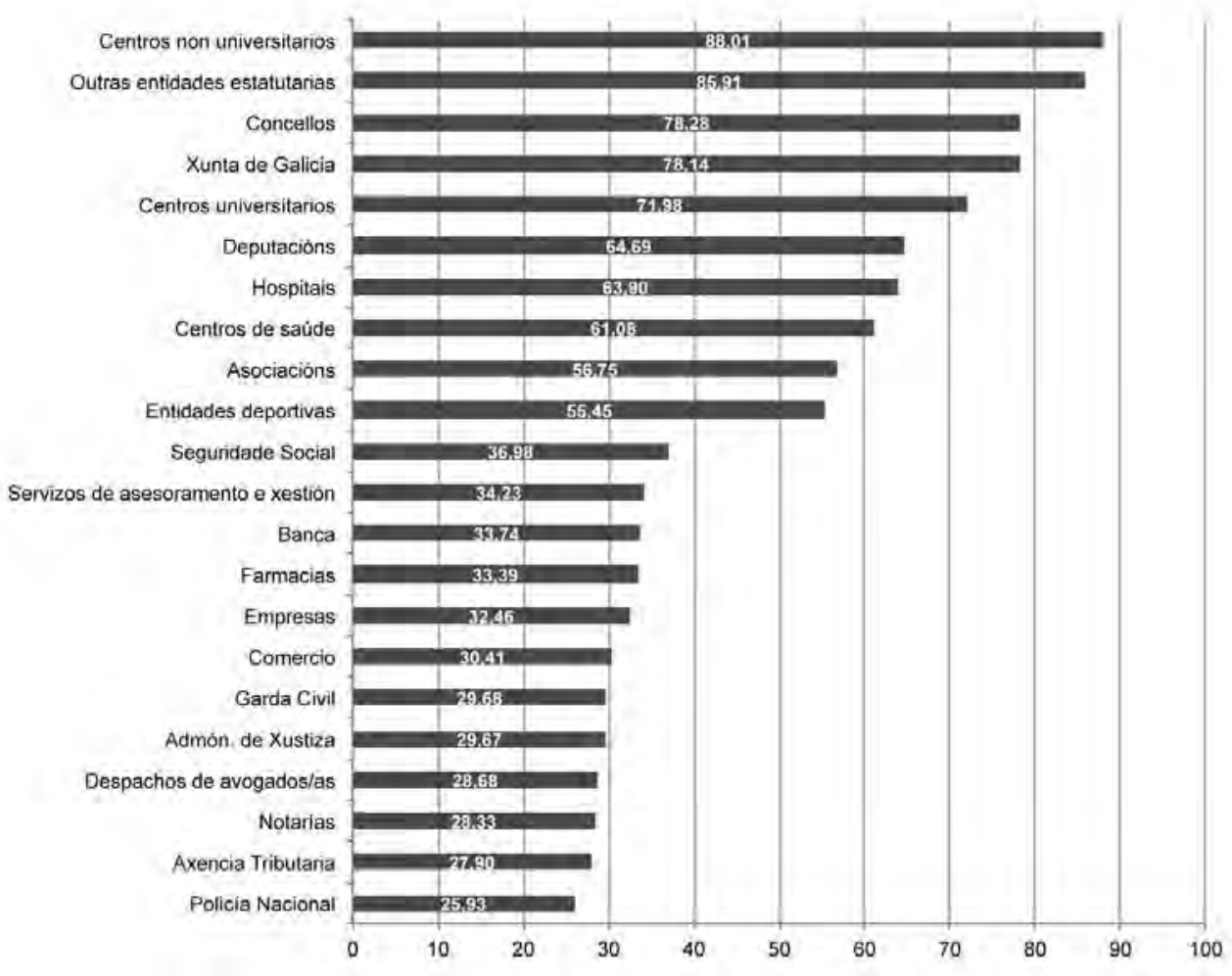


- Táboa 15. Lingua habitual da cidadanía

\begin{tabular}{lllllll} 
& Só galego & $\begin{array}{l}\text { Máis galego } \\
\text { ca castelán }\end{array}$ & As dúas igual & $\begin{array}{l}\text { Máis castelán } \\
\text { ca galego }\end{array}$ & Só castelán & Outras linguas \\
\hline Total & 30,24 & 17,72 & 19,28 & 18,8 & 13,76 & 0,2 \\
\hline
\end{tabular}

Base: poboación de 15 anos ou máis residente en Galicia en 2007

Fonte: Observatorio da Lingua Galega

- Táboa 16. Comparativa das competencias entre o galego e o castelán

\begin{tabular}{llll} 
& Galego & Castelán & As dúas igual \\
\hline Total & 6,96 & 74,36 & 18,68 \\
\hline
\end{tabular}

Base: poboación de 15 anos ou máis residente en Galicia en 2007

Fonte: Observatorio da Lingua Galega

- Táboa 17. Evolución do cambio de lingua

\begin{tabular}{lll} 
& Máis galego & Máis castelán \\
\hline Total & 78,2 & 21,8 \\
\hline
\end{tabular}

Base: poboación de 15 anos ou máis residente en Galicia en 2007

Fonte: Observatorio da Lingua Galega

Os indicadores de opinión seguen a reflectir a existencia dun consenso sólido arredor da conveniencia das políticas que potencien o uso e a utilidade do galego e a súa pertenza ao corpo central da identidade nacional.

- Táboa 18. Opinión sobre a potenciación do uso do galego

\begin{tabular}{llllll} 
& $\begin{array}{l}\text { Totalmente } \\
\text { de acordo }\end{array}$ & $\begin{array}{l}\text { Bastante } \\
\text { de acordo }\end{array}$ & Indiferente & $\begin{array}{l}\text { Bastante } \\
\text { en desacordo }\end{array}$ & $\begin{array}{l}\text { Totalmente } \\
\text { en desacordo }\end{array}$ \\
\hline Total & 62,48 & 23,76 & 4,52 & 6,4 & 2,84 \\
\hline
\end{tabular}

Base: poboación de 15 anos ou máis residente en Galicia en 2007

Fonte: Observatorio da Lingua Galega 
- Táboa 19. Evolución do galego

\begin{tabular}{llll} 
& Diminuíu/diminuirá & Segue igual/seguirá igual & Aumentou/aumentará \\
\hline Total & 13,92 & 34 & 52,08 \\
\hline
\end{tabular}

Base: poboación de 15 anos ou máis residente en Galicia en 2007

Fonte: Observatorio da Lingua Galega

- Táboa 20. Opinión sobre o galego como signo de identidade de Galicia

\begin{tabular}{llllll} 
& $\begin{array}{l}\text { Totalmente } \\
\text { de acordo }\end{array}$ & $\begin{array}{l}\text { Bastante } \\
\text { de acordo }\end{array}$ & Indiferente & $\begin{array}{l}\text { Bastante } \\
\text { en desacordo }\end{array}$ & $\begin{array}{l}\text { Totalmente } \\
\text { en desacordo }\end{array}$ \\
\hline Total & 49,72 & 33 & 2,72 & 10 & 4,56 \\
\hline
\end{tabular}

Base: poboación de 15 anos ou máis residente en Galicia en 2007

Fonte: Observatorio da Lingua Galega

O cambio Bipartito: novo problema, nova regulación, novos instrumentos

O cambio impulsado polo Bipartito ten a súa causa nunha nova definición do problema, que pasa por cambiar o concepto de «bilingüismo harmónico» polo de «normalización lingüística». Ou, dito doutro xeito, a política de máximos do PP convértese no mínimo, no punto de partida da política que vai formular o Bipartito.

Dunha política baseada na idea de que as dúas linguas gozan dun status semellante e que o obxectivo ten que ser o de garantir o seu uso "harmónico», pásase a definir o problema en termos de desigualdade: unha das dúas linguas está en posición de inferioridade é e preciso pór en marcha políticas activas que produzan un resultado de normalización que por si só non se vai producir.

Da política do «bilingüismo harmónico» pásase á posta en marcha dunha verdadeira estratexia de normalización lingüística, guiada polo plan de normalización lingüística aprobado por unanimidade no Parlamento en 2004. Dese xeito, o documento parlamentar deixa de ser un instrumento simbólico para converterse no referente para o desenvolvemento dunha nova política que implica cambios organizativos, regulativos e de volume de recursos asignados. 


\section{Cambio na Administración e organización do problema}

O primeiro sinal do cambio será a relocalización no organigrama da Xunta. Política Lingüística abandona a visión sectorial que lle confire a súa adscrición en Educación, para pasar a ser unha Secretaría Xeral con dependencia directa da Presidencia do Goberno e unha visión interdepartamental das súas competencias e do seu traballo de impulso e potenciación do uso do galego en todos os eidos da vida galega.

Este cambio ampliou de xeito notorio tanto as competencias como a capacidade de acción do departamento de Política Lingüística e trouxo consigo a implantación dos informes de política lingüística para a acción regulativa e lexislativa do goberno ou a posta en marcha de numerosas iniciativas de carácter interdepartamental para impulsar o galego no conxunto da Administración e nas áreas de xestión. Pero, sobre todo, significou un xesto simbólico e político de alcance respecto á importancia que se lle quería dar ao proceso de normalización lingüística. Non é, polo tanto, casualidade que unha das primeiras medidas que toma Feijóo en materia de política lingüística sexa devolver o departamento á Consellería de Educación e quitarlle o seu carácter transversal e interdepartamental.

\section{Cambio na regulación do problema}

Sen dúbida, o cambio máis potente prodúcese no ámbito regulativo, co Decreto $124 / 2007$ do 28 de xuño. É o texto legal no que se plasma xuridicamente esa nova definición do problema como un proceso de normalización lingüística, non como un proceso de "harmonía» de igualdade entres dúas linguas iguais. $\mathrm{O}$ Decreto toma como punto de partida os «máximos» da política lingüística na Era Fraga e fixa novos obxectivos e resultados, en sintonía cos previstos no Plan de 2004:

- fíxase como mínimo o $50 \%$ da docencia en galego en todos os niveis educativos, agás no universitario;

- fíxanse as materias obrigatoriamente para impartir en galego, e elimínase a autonomía case total que tiñan os centros;

- potenciación da figura dos equipos de normalización e dinamización lingüística;

- fíxase un proceso anual de avaliación dos avances do proceso de normalización. 


\section{Incremento de orzamentos}

O Bipartito trouxo canda el un significativo aumento dos orzamentos dedicados exclusivamente á política lingüística, que medran por riba da media de crecemento doutras partidas de gasto. En troques, o primeiro goberno Feijóo trouxo un significativo recorte que devolve o orzamento ás cifras de 2004.

- Partida orzamentaria destinada polo goberno da Xunta de Galicia á Política Lingüística entre os anos 2002-2009

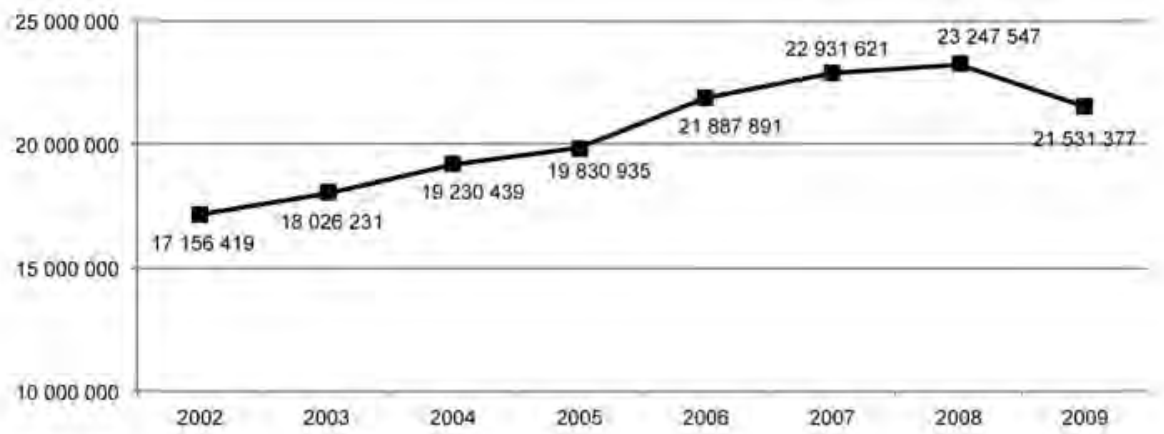

\section{ACTORES E ESTRATEXIAS: UNHA HIPÓTESE SOBRE A FORMULACIÓN DOS DISTINTOS MODELOS DE POLÍTICA LINGÜÍSTICA EN GALICIA}

A análise dos datos achegados até o de agora permiten constatar:

(i) a existencia dun consenso social sólido, estable e duradeiro arredor tanto da necesidade de potenciar e mellorar a situación do galego (máis do 70\%) e da importancia do galego como elemento da identidade colectiva;

(ii) que as competencias respecto do galego melloraron notablemente pero sen que iso supuxese unha redución ou empeoramento das competencias con respecto ao castelán, que de lonxe segue a ser a lingua que goza dunha mellor situación en termos de competencia e presenza social; e 
(iii) que o cambio de política impulsado polo goberno bipartito tiña impactos sobre todos os inputs da política (organización, regulación, orzamentos) e non producira aínda efectos significativos sobre os resultados das políticas lingüísticas.

A irrupción da "cuestión lingüística» no debate político, e sobre todo na campaña electoral das Galegas 2009, non responde a cambios nos resultados das políticas, nin tan sequera a unha modificación substancial das percepcións e valoracións do conxunto da opinión galega sobre a orientación, o alcance ou os contidos desas políticas. Semella axeitado, polo tanto, formular como hipótese que a aparición do denominado "conflito lingüístico» responde a estratexias e comportamentos dos actores, máis que á existencia dun conxunto de condicións relativas á situación real dos dous idiomas, o rendemento do sistema educativo ou variacións significativas nas percepcións colectivas.

Para analizar as estratexias dos diferentes actores e a súa evolución como factores explicativos do estalido do «conflito» é de grande utilidade a ferramenta dos «roles» de Bruno Dente. De acordo co modelo, no escenario que conforma unha política pública, os diferentes actores desempeñan una serie de roles ou papeis na formulación e na súa implementación. Dente identifica os seguintes roles:

- O Promotor, que é o actor ou actores que erguen o problema e a súa definición, activa os outros actores para armar coalicións de apoio e abandeira unha solución. O que o move é o contido da política.

- O Director, que é o actor ou actores interesados en obter un resultado, necesita que haxa unha política con relativa independencia dos problemas de desenvolvemento do proceso ou das consecuencias non desexadas.

- O Opositor, que é o actor ou actores que desempeñan en contra da política animada polo promotor.

- O Mediador, que é o actor ou actores interesados máis polo proceso de produción da política que polo contido desta. O que lle importa é o grao de consenso da solución, máis incluso que a propia solución en canto que é ese consenso o que lexitima a súa presenza na política. Non ten por que ter unha definición propia.

- O Filtrador, que é o actor ou actores que non teñen un interese específico na política pero ou ben actúa como voceiro doutro que si o ten ou ben a utiliza estratexicamente para gañar posición noutra política. 
- O Porteiro, que é aquel actor ou conxunto de actores que dispón do poder de frear ou vetar una solución concreta. Non ten un interese específico ou concreto na política, pero sen o seu consenso non é posible tomar unha decisión.

\section{O bilingüismo harmónico como equilibrio}

A política de «bilingüismo harmónico» que deseña e implementa a Xunta de Fraga responde ás necesidades da estratexia política desenvolvida por Manuel Fraga dende a súa volta a Galicia. É o produto da súa busca consciente do chamado "espazo galeguista» para asegurar a maioría absoluta axustada que conseguiu en 1989. A ocupación dese espazo cun uso estratéxico e simbólico das políticas da Xunta máis vencelladas á cuestión identitaria son un elemento clave da estratexia política e de crecemento electoral desenvolvida por Fraga con notable éxito e que lle permitiu revalidar e ampliar sucesivas maiorías absolutas e eliminar a competencia por ese espazo electoral que podían supor os restos de Coalición Galega.

O bilingüismo harmónico ofrécelle tamén ao PP a posibilidade de reforzar a lexitimidade do seu discurso galeguista ao presentarse a si mesmo como a forza que garante o equilibrio e unha solución de consenso entre as diversas posicións en materia de promoción e defensa da lingua. A política funciona tamén en certo grao como garantía fronte aos grupos máis radicais tanto a favor do galego como do castelán.

Neste escenario, o repartimento de roles entre os diferentes actores configúrase de tal xeito que:

- O pP actúa como Promotor do modelo do bilingüismo harmónico, é a súa solución da cuestión lingüística, activa os outros actores e impulsa a coalición de apoio baseado nun equilibrio en que aos partidarios dunha política lingüística de normalización se lles ofrece o dominio teórico e declarativo da política e aos contrarios á normalización a garantía de que a súa aplicación e implementación van ser voluntarias.

- A Xunta que preside Fraga actúa como Director en canto actor interesado en obter o resultado dunha política lingüística e relativa despreocupación sobre os problemas de implementala. 
- Como Opositores actúan a Mesa pola Normalización Lingüística e as organizacións tipo Galicia Bilingüe, porque o modelo do bilingüismo harmónico non cumpre as súas expectativas a prol do galego ou do castelán, e o poderoso lobby da educación privada e concertada resistente á expansión do galego no sistema educativo polos custos que lles vai supor.

- O PP desempeña tamén un papel clave como Mediador, en canto que o modelo do bilingüismo harmónico se centra máis no proceso de produción da política ca no seu propio contido. O que lle importa é o grao de consenso da política, máis incluso que a propia efectividade na potenciación ou defensa do galego, en canto que ese consenso reforza a súa lexitimidade.

- O PSOE desempeñaría nesta etapa o rol de Filtrador en canto que non ten un interese específico na política, pero si a vai utilizar estratexicamente para gañar posicións no escenario político. 
- Figura 1. Roles e actores na política do bilingüismo harmónico

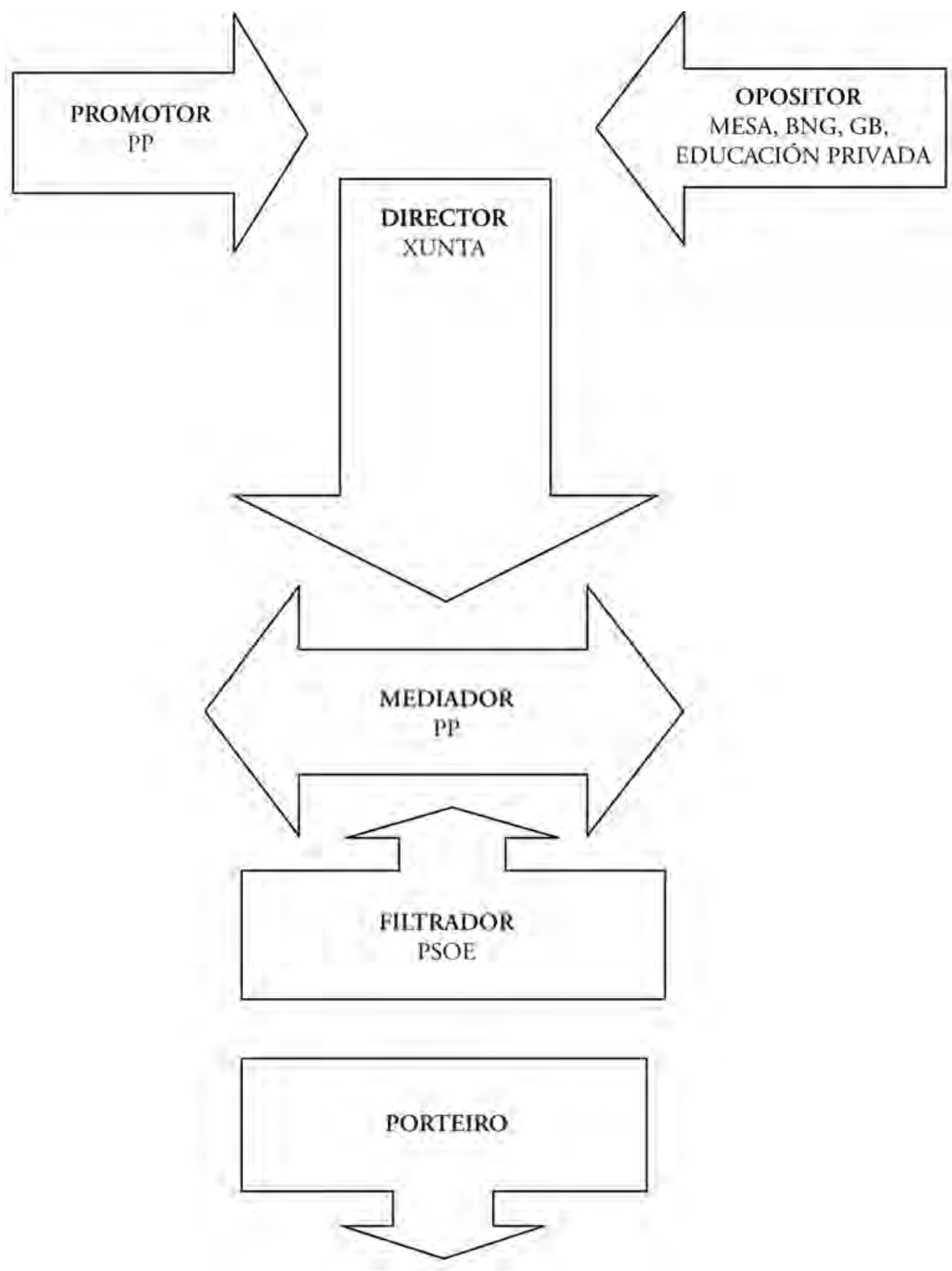




\section{Do equilibrio harmónico á normalización inestable}

O cambio de política impulsado polo Bipartito altera significativamente os roles desenvolvidos até o de agora e, sobre todo, altera a solución de equilibrio que era o bilingüismo harmónico e despraza o PP da súa posición de centralidade, ao tempo que habilita a formación dunha poderosa coalición contra o modelo da normalización.

- BNG e PSOE pasan a desenvolver o rol de Promotores do modelo da normalización. Aínda que con distinta intensidade e compromiso por parte de cada quen, é a súa solución da cuestión lingüística.

- A Xunta Bipartita segue a actuar como Director en canto actor interesado en obter o resultado dunha política lingüística que garanta a estabilidade da coalición de goberno e unha relativa despreocupación sobre os problemas de implementala.

- Como Opositores mantense a Mesa pola Normalización Lingüística ao considerar insuficiente a política, pero a novidade é que se conforma unha poderosa coalición en contra da nova política, a que conforman as organizacións tipo Galicia Bilingüe, que a perciben como unha ameaza, e o poderoso lobby da educación privada e concertada resistente á expansión do galego no sistema educativo polos custos que lles vai supor, e o Partido Popular, conscientes da dominación sen competencia do espazo electoral que Fraga pretendía ocupar e busca achegarse a un voto urbano que ou ben se lle escapara cara ao Bipartito ou ben ve ameazado por novos competidores coma Rosa Díez. Ao mesmo tempo, hai tamén unha oposición que ten que ver co seu propio modelo de política lingüística, baseado na idea de voluntariedade do proceso.

- No novo escenario ningún actor desempeña o rol de Mediador. Ningún actor —ou se acaso o PSOE, pero de xeito irregular — asume o papel que representaba o PP no modelo do bilingüismo harmónico, que se centraba máis no proceso de produción da política ca no seu propio contido. Iso tradúcese no abandono dunha das claves do éxito político do modelo Fraga: que lle importase máis o grao de consenso da política cá propia efectividade na potenciación ou defensa do galego ou do castelán.

- O pP desempeña nesta etapa o rol de Filtrador en canto que a súa oposición á política a utiliza estratexicamente para gañar posicións no escenario político.

- Outra novidade no escenario é que aparecen tamén actores que desempeñan o papel de Porteiros. Tanto o Goberno Central do PP e do PSOE como a dirección estatal do PP traducen a crecente relevancia da cuestión lingüística na política estatal nunha maior disposición a tutelar ou vetar o que se decida en Galicia, para poder 
frear ou vetar una solución que poida ser percibida ou presentada fóra de Galicia coma unha «ameaza» contra o castelán.

- Figura 2: Roles e actores na política da normalización

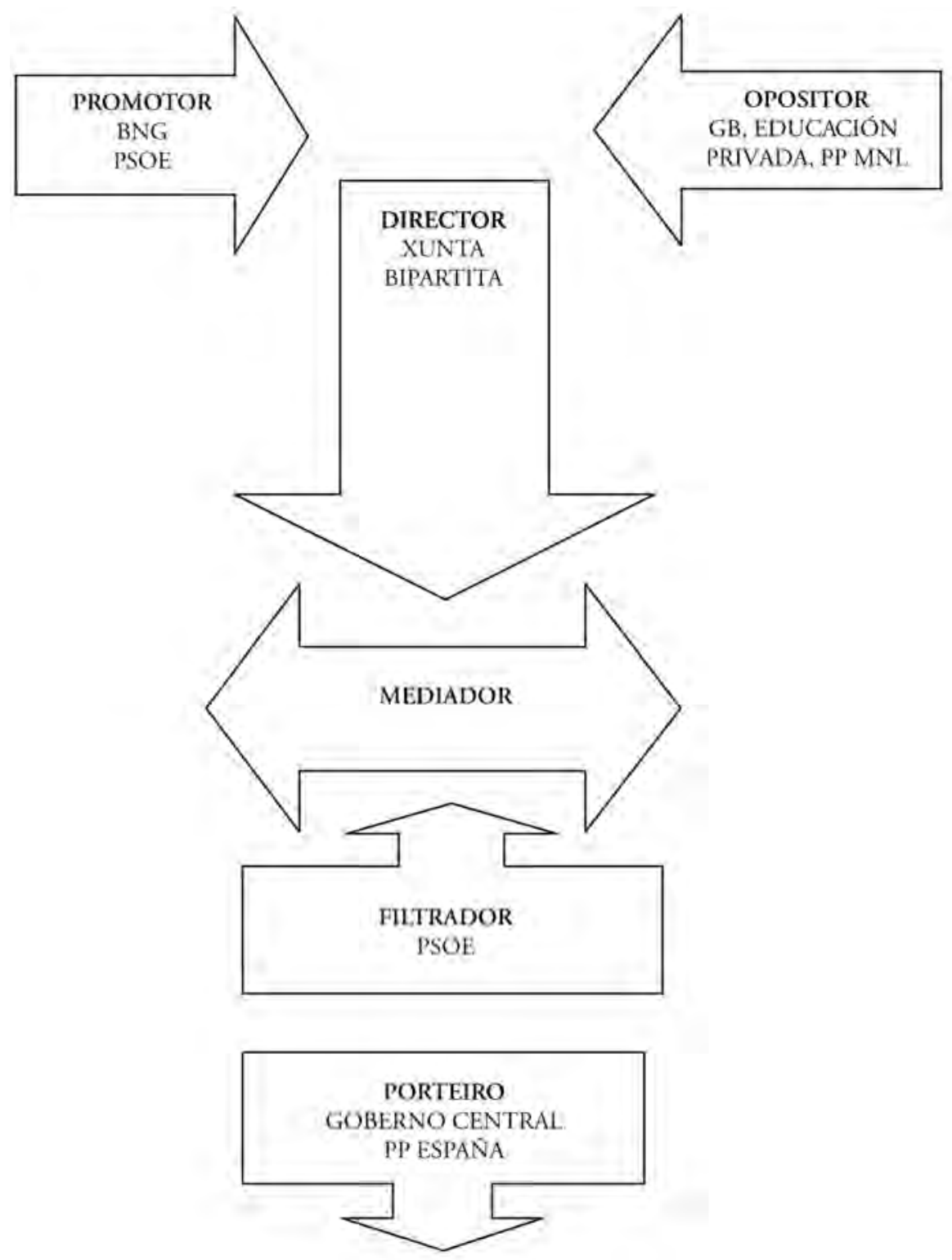




\section{A emerxencia do bilingüismo cordial}

A nova estratexia impulsada por Feijóo durante a campaña electoral non pode explicarse unicamente en termos electorais ou de coxuntura electoral. É un movemento estratéxico que busca asegurar un dobre resultado:

1. Recuperar o papel de centralidade que lle asignaba ao PP o modelo do bilingüismo harmónico e que reforzaba a súa posición hexemónica na competencia política e electoral, coa prevención da aparición de posibles competidores polo espazo galeguista ou nacionalista moderado.

2. Impedir a consolidación dun novo escenario político de xestión moi difícil para os populares galegos, dado que comporta un agravamento das contradicións internas que supón o discurso pseudogaleguista fronte ao discurso neoespañolista da dirección estatal. $\mathrm{O}$ avance do proceso de normalización agudiza esas contradicións coa dirección estatal do partido e, sobre todo, despraza da súa privilixiada posición de centralidade o PP de G, o que lle podería supor arriscar importantes espazos electorais e sociais tanto a competidores na defensa do castelán como competidores nacionalistas.

Para lograr ese dobre obxectivo, o PP necesita cambiar o seu rol e volver desempeñar ese dobre papel de promotor e mediador que lle deu a posición central no modelo do bilingüismo harmónico.

- O PP volve desenvolver o rol de Promotor do modelo do bilingüismo cordial, como nova solución de equilibrio mantendo os elementos simbólicos dunha política de normalización, pero tornando á voluntariedade da implementación do modelo bilingüe.

- A Xunta segue actuando como Director en canto actor interesado en obter o resultado dunha política lingüística que garante a estabilidade da coalición de goberno e unha relativa despreocupación sobre os problemas de implementala.

- De novo nos roles Opositores é onde se produce o cambio significativo: refórzase a coalición a prol da normalización, coa suma á Mesa, do PSOE e do BNG e de novas plataformas emerxentes. Pero ao tempo, mantense viva a poderosa coalición contraria á normalización e tamén contraria á nova política; as organizacións tipo Galicia Bilingüe, o poderoso lobby da educación privada e unha parte importante do Partido Popular rexeitan que se manteñan na política os elementos simbólicos dunha política de normalización e reclaman que o 
discurso da libre elección non se limite á implementación senón que se converta no contido da política.

- No novo escenario, segue sen haber actores para o rol de Mediador, ningún actor traballa por un proceso de produción consensuada da política.

- O PP estatal vai seguir desempeñando o papel de Porteiro vixiante de que a nova política de Feijóo non se aparte da ortodoxia do discurso da defensa do castelán.

- Figura 3: Roles e actores na política do bilingüismo cordial

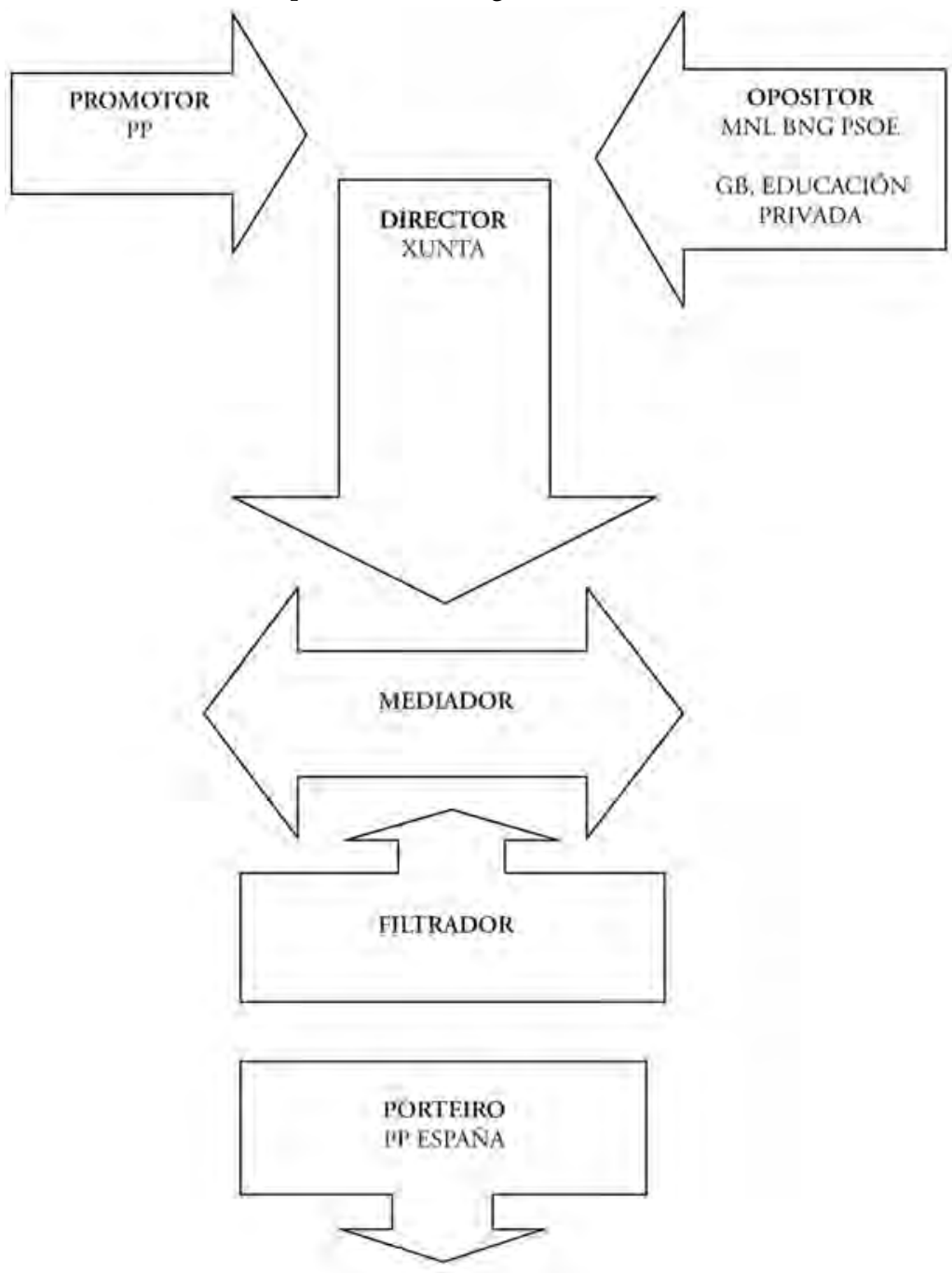


Esta nova distribución de roles é un elemento clave para explicar a actual situación de indefinición respecto da política lingüística e as indecisións e contradicións que ten acreditado o goberno Feijóo.

En primeiro lugar, e rachando co que era unha das constantes históricas en Galicia nesta materia, armáronse dúas poderosas coalicións con definicións totalmente opostas e excluíntes entre si do que debe ser unha política de potenciación do galego. Mantense o gran consenso social arredor do desexable dese tipo de políticas, pero agrandáronse as diferenzas na interpretación do seu significado.

En segundo lugar, o PP dende a Xunta non dá atopado o xeito de volver colocarse como ese actor-mediador que facilite o consenso entre os dous extremos, xa que ningunha das coalicións lle recoñece ese papel. Dito doutro xeito, para evitar ser desprazado da súa centralidade, o PP moveuse estratexicamente e acabou perdendo a súa posición central como resultado da súa propia manobra.

Agora quere promover un modelo baseado nun consenso que rachou e que non pode volver reconstruír porque unha maioría dos restantes actores lle nega a lexitimidade para desempeñar ese rol, de aí que busque vías alternativas de lexitimación como a consulta aos pais, as constantes apelacións ao consenso ou o incerto proceso de diálogo que semella querer iniciar logo do éxito das sucesivas mobilizacións cidadás en defensa da súa lingua. 


\section{BIBLIOGRAFÍA}

ARgelaget, J.: «Las políticas lingüísticas: diversidad de modelos lingüistico-escolares», en SUBIRATS Y Goma (eds.), Políticas públicas en España, Barcelona, 1998, pp. 294-316.

Cabrera Varela, J.: «Las precondiciones sociales de la identidad colectiva de Galicia», Historia y Crítica, Madrid, n. ${ }^{\circ}$ 4, 1994, pp. 209-239.

- e J. Rivera Otero (dirs.): Barómetro galego 1998: Actitudes, valores e cultura política, Santiago de Compostela, Facultade de Ciencias Políticas, Universidade de Santiago de Compostela, 1998.

Dowding, K. \& D. KInG: Preferences, Institutions and Rational Choice, Oxford, Clarendon, 1995.

A ECONOMÍ galega. Informe 1995-1997, Santiago de Compostela, Instituto de Estudios e Desenvolvemento de Galicia, Universidade de Santiago de Compostela, Fundación Caixa Galicia, 1997.

GonZÁlez, L. M.: Bilingüismo en Galicia: Problemas y alternativas, Santiago de Compostela, Universidade de Santiago de Compostela, 1985.

INFORME España 1996. Una interpretación de su realidad social, Madrid, Fundación Encuentro, 1997, n. 4.

Lameiras Fernández, M. e M. González Lorenzo: «Los usos lingüísticos en Galicia», Revista Galega de Psicopedagoxía, n. ${ }^{\circ}$ 13, vol. 9, 1996, pp. 161-178.

— «Las actitudes lingüísticas en Galicia», Revista Galega de Psicopedagoxía, n. ${ }^{\circ}$ 13, vol. 9, 1996, pp. 179-192.

Losada TRABADA, A.: La política del mar: El impacto de una politica sobre la consolidación institucional de la Autonomía. Análisis de la Politica de Pesca en Galicia, Madrid, Istmo, 2000.

Márz SuÁreZ, R.: «Nación de Breogán: Oportunidades políticas y estrategias enmarcadoras en el Movimiento Nacionalista Gallego (1886-1996)», Revista de Estudios Políticos, Nueva época, n.o 92, abrilxuño, 1996, pp. 33-78.

— "Estrategias e institución: El análisis de las dimensiones macro del clientelismo político», en ANTONIO Robles (comp.), Politica en penumbra, Madrid, Siglo XXI editores, 1996.

- A idea de nación, Vigo, Xerais, 1997.

— «Nacionalismo y movilización política: un análisis pluridimensional de la construcción de las naciones», Zona Abierta, Madrid, 1997, pp. 168-216.

Reig Martínez, E. e A. J. PiCazo TadeO: Capitalización y crecimiento de la economía gallega. 1955-1996, Bilbao, Fundación BBV, 1997.

Rojo, G.: «La situación lingüística gallega», Revista de Occidente, 10-11, 1982, pp. 93-110.

RUBAL, J.: Aproximación á situación da lingua no ensino non universitario (preescolar e EXB), Santiago de Compostela, Xunta de Galicia, 1992.

SEminario de Sociolingứ́stica da ReAl ACAdEMIa Galega: Lingua inicial e competencia lingüistica en Galicia, A Coruña, Real Academia Galega, 1994.

- Usos lingüisticos en Galicia, A Coruña, Real Academia Galega, 1995.

- Actitudes lingüisticas en Galicia, A Coruña, Real Academia Galega, 1996.

Smith, A. D.: Nationalism and Modernism, Londres, Routledge, 1998.

Stavenhagen, R.: Ethnic Conflicts and the Nation-State, Londres, Macmillan, 1996.

SCHARPF, F.: Actor-Centered Institutionalism in Policy Research, Boulder, Westview, 1997.

Weaver, R. \& B. Rockman: Do Institutions matter?, Washington, Brookings, 1993. 
